\title{
Neither thermosonication nor cold sonication is better than pasteurization for milk shelf life
}

\author{
Seung-Yong Lim, ${ }^{1}$ Lily Claire Benner, ${ }^{2}$ and Stephanie Clark ${ }^{2 *}$ \\ ${ }^{1}$ Department of Food Science and Biotechnology, Kunsan National University, Gunsan 54150, Republic of Korea \\ ${ }^{2}$ Department of Food Science and Human Nutrition, lowa State University, Ames 55011-1052
}

\begin{abstract}
High-power, low-frequency ultrasound has been suggested as a novel processing technique with the potential to extend milk shelf life via inactivation of bacteria and spores that survive standard pasteurization. The primary objective of this research was to determine whether short-duration ( $\leq 60 \mathrm{~s})$ sonication treatment, in conjunction with pasteurization, can increase shelf life while producing no adverse aroma effect. Skim milk was inoculated with Paenibacillus amylolyticus, a spore-forming, thermotolerant and psychrophilic milk contamination bacterium. Milk was sonicated under 6 selected amplitude and time conditions, except for control. Both cold sonicated (C-S) and thermosonicated (T-S) milk and milk treatments were pasteurized; however, T-S milk was sonicated after pasteurization (72.5 $\pm 0.3^{\circ} \mathrm{C}$; mean $\left.\pm \mathrm{SD}\right)$, whereas $\mathrm{C}$-S milk was sonicated at $12.5 \pm 5^{\circ} \mathrm{C}$ (mean $\pm \mathrm{SD}$ ) before pasteurization. Milk was refrigerated up to $50 \mathrm{~d}$ and total aerobic counts were enumerated on pasteurized control, C-S, and T-S milk weekly. Neither C-S nor T-S treatments reduced total aerobic counts to an equivalent level as pasteurization alone. Counts in pasteurized controls and C-S milk did not exceed $3.00 \mathrm{log} \mathrm{cfu} / \mathrm{mL}$ for up to $50 \mathrm{~d}$; counts in T-S milk exceeded $5.00 \mathrm{cfu} / \mathrm{mL}$ by d 36. Aroma qualities (cooked, lacks freshness, and rubbery) of 2 T-S treatment intensities $[170 \mu \mathrm{m}$ peak-to-peak (p-p) for $60 \mathrm{~s}$ and $200 \mu \mathrm{m}_{\mathrm{p}-\mathrm{p}}$ for $10 \mathrm{~s}$ ] and pasteurized controls were evaluated by a trained descriptive sensory panel. No significant differences were observed in cooked or lacks freshness aromas among samples. Only the milk treated with $170 \mu \mathrm{m}_{\mathrm{p}-\mathrm{p}}$ for $60 \mathrm{~s}$ had significantly higher rubbery aroma on d 1 compared with milk treated with $200 \mu \mathrm{m}_{\mathrm{p}-\mathrm{p}}$ for $10 \mathrm{~s}$. Although the sensory effects of T-S on milk may not limit the commercial feasibility of cold sonication or thermosonication, conditions that differ from those used in the present study should be consid-
\end{abstract}

Received July 9, 2018.

Accepted January 19, 2019

*Corresponding author: milkmade@iastate.edu ered in the future. Neither C-S nor T-S were appropriate techniques for reducing bacterial count in fluid milk beyond standard pasteurization and, in fact, increased counts of spore-forming spoilage bacteria.

Key words: quality, sensory, spores, ultrasound

\section{INTRODUCTION}

Fluid milk competes with beverages that have a long shelf life (Fromm and Boor, 2004). One way to increase fluid milk's marketability is to improve quality and extend shelf life (Boor, 2001; Fromm and Boor, 2004). Shelf life can be extended through ultrapasteurization or UHT processing and aseptic packaging; however, quality is changed at the higher temperatures because of Maillard or caramelization reactions (Clare et al., 2005) and an increase in sulfur compounds (Zabbia et al., 2012). These processes can result in off-flavors that are unacceptable to some consumers (Christensen and Reineccius, 1992). Standard pasteurization does not compromise the sensory quality and nutritional properties of milk (Gandy et al., 2008), but alternative processing techniques are sought to improve some aspects of milk flavor, shelf life, or other functionality. Some nonthermal technologies have emerged as alternative processes to minimize changes in sensory properties induced by extreme heating. Emerging technologies such as high-pressure processing (García-Risco et al., 2003; Borda et al., 2004; Bilbao-Sainz et al., 2009), pulsed electric field (Bendicho et al., 2005), and ultrasound (Vercet et al., 2002) have been explored to investigate their potential to inactivate shelf life-limiting enzymes but maintain milk quality.

Ultrasound is acoustic vibration by cyclic sound pressure waves of frequencies beyond the human hearing range, including power ultrasound (16 to $100 \mathrm{kHz}$ ), high-frequency ultrasound (100 kHz to $1 \mathrm{MHz})$, and diagnostic ultrasound (1 to $10 \mathrm{MHz}$ ) (Patist and Bates, 2008). In contrast to low power diagnostic ultrasound (less than $1 \mathrm{~W} / \mathrm{cm}^{2}$ ), high-power ultrasound is typically defined as 16 to $100 \mathrm{kHz}$ frequency and 10 to 1,000 $\mathrm{W} / \mathrm{cm}^{2}$ power density (Soria and Villamiel, 2010). 
Sonication has a complex mechanism, and therefore its wide-ranging effects on the treatment medium must be examined carefully. The power of an ultrasonic device is characterized by the amount of energy (joules) passed through to the medium per second. Some researchers report ultrasonic treatments in terms of intensity, or watts per area; however, Zisu et al. (2013) chose to use energy density, or joules per volume of liquid. Energy density is a result of treatment at a set frequency and power defined by the ultrasonic device, and it is subject to change depending on the selected amplitude and duration of treatment. The technology relies on the application of pressure waves to a liquid food material and alternating regions of high and low pressures, which induce cavitation and form gas or vapor bubbles (Nguyen and Anema, 2010; Pingret et al., 2012). Some authors also use the term cavitation to describe the bubble growth and subsequent collapse with considerable energy release, which induces localized extreme conditions and leads to bacterial cell death (Ashokkumar, 2011; Gogate, 2011; Wu et al., 2013; Juliano et al., 2014; Khanal et al., 2014a).

One reason behind the limited shelf life of milk is the presence of bacterial spores in milk that are unaffected by pasteurization, even at the temperatures of ultrapasteurization (Hantsis-Zacharov and Halpern, 2007). Psychrotrophic strains such as spore-forming Bacillus and Paenibacillus are predominant in the raw milk supply (Martin et al., 2011). They are common contaminants in the farm environment, often associated with soil, feed, or manure, and the thermoduric psychrotrophs common to milk are also spore-forming bacteria (Meer et al., 1991). Spores, the dormant forms of bacteria, are resistant to extreme temperatures, acid, alkalinity, and oxidizing agents (Khanal et al., 2014a). The main drawback of psychrotrophic strains in milk is their ability to produce extracellular enzymes, mainly proteases and lipases, which are responsible for spoiling milk and finished or processed dairy products, as the extracellular enzymes can resist pasteurization and even UHT processing (Hantsis-Zacharov and Halpern, 2007). Furthermore, the pasteurization process may promote activation and result in more rapid outgrowth of some spore-forming bacteria (Huck et al., 2007). Consequently, if Paenibacillus spores are present, they can germinate and proliferate during refrigerated storage, leading to spoiled, bitter-tasting milk (Fromm and Boor, 2004; Ranieri and Boor, 2009). As heat alone is not able to destroy the thermotolerant spores of microorganisms such as Bacillus and Paenibacillus, researchers have turned to other technologies as a means of killing bacteria in dairy products.

The inactivation of bacteria using ultrasound was first initiated in the 1920s (Harvey and Loomis, 1929).
Some researchers have shown the ability of high-power ultrasound to kill bacteria, inactivate enzymes, and improve the cheese- or yogurt-making process (Villamiel and de Jong, 2000; Reiner et al., 2009b; Martini and Walsh, 2012; Shanmugam et al., 2012). High-power ultrasound has proven to be useful in inactivating microorganisms (Wrigley and Lorca, 1992; Villamiel and de Jong, 2000; Cameron et al., 2008, 2009), suggesting potentials to extend shelf life of fluid milk. However, the effect of ultrasound alone has been considered ineffective for the inactivation of bacterial spores (Butz and Tauscher, 2002).

Some researchers observed higher inactivation of microorganisms and enzymes when ultrasound was combined with factors such as heat or with heat and pressure (Lopez et al., 1994; Vercet et al., 2002; Manas et al., 2006; Czank et al., 2010). Villamiel and de Jong (2000) were among the first to promote the use of thermosonication (simultaneous thermal processing and ultrasound), reporting that a synergistic effect of heat and ultrasound was much higher for inactivating enzymes and reducing microbial load compared with ultrasound or heating alone. However, thermosonication has been associated with off-odor and off-flavor formation in milk, a phenomenon that has been studied but not entirely explained. The sensory quality of milk is of the utmost importance to consumers (Bus and Worsley, 2003), so the detrimental sensory effects of ultrasound must be overcome if ultrasound is to be taken seriously as an alternative processing method. Ultrasound energy can induce peroxide formation from water hydrolysis, which can lead to radical oxidation of milk lipids and off-flavor compounds (Chouliara et al., 2010; Reiner et al., 2009b; Marchesini et al., 2015). Some studies have suggested that even short periods of ultrasound treatment result in undesirable sensory attributes (Chouliara et al., 2010; Marchesini et al., 2015). Aroma compounds were studied from a sensory perspective by Chouliara et al. (2010), who found that panelists' acceptance of samples was lower for thermosonicated [at $200 \mathrm{~W}$, approximately $240 \mu \mathrm{m}$ peak-to-peak (p-p), for $2 \mathrm{~min}]$ samples as compared with untreated milk. Both Reiner et al. (2009a) and Chouliara et al. (2010) cited a foreign, rubbery, or burnt chemical taste in thermosonicated samples, which panelists found objectionable. In contrast, the use of thermosonication $\left(152 \mu \mathrm{m}_{\mathrm{p}-\mathrm{p}}\right)$ for 1 to 3 min decreased $94 \%$ of plasmin activity in raw skim milk and cream and increased the microbial shelf life of skim milk without sacrificing sensory quality (Vijayakumar et al., 2015).

Ultrasound treatments have been reported to damage cell membranes, causing them to buckle inward to varying degrees, as well as causing spores to wrinkle and shrink (Cameron et al., 2008). Static trials using 
batch ultrasonication were found effective in reducing Bacillus spores in nonfat milk (Khanal et al., 2014a). Yet in some applications, ultrasound has been used to stimulate bacterial growth. Khanal et al. (2014b) reported that increased ultrasonication amplitude might induce sporulation rather increase endospore inactivation level. Low, sublethal doses of ultrasound can bust up clumps of cells, increasing total counts or colony-forming units (Marchesini et al., 2015). Gao et al. (2014) found that the sensitivity to ultrasound does not depend on the size, the Gram status, or the hydrophobicity of bacteria, but rather on the thickness of the polysaccharide as well as the softness of the protein capsule, which is a highly hydrated layer external to the plasma membrane that is composed of homogeneous polysaccharides and proteins that contribute to maintaining cellular integrity (Marchesini et al., 2015)

Research involving the effects of sonication or thermosonication on milk quality typically employ treatment times exceeding $1 \mathrm{~min}$ at various power or amplitude levels, which is not practical in fast-paced commercial HTST operations. More research needs to be done to determine the minimal amount of ultrasound treatment needed to induce desired microbial and enzymatic changes to milk without damaging sensory quality. The purpose of our study was to determine whether thermosonication (ultrasound treatment after pasteurization) or cold sonication (ultrasound treatment in an ice bath followed by pasteurization) is more or less effective at reducing aerobic bacteria compared with pasteurization alone while not damaging milk sensory quality.

\section{MATERIALS AND METHODS}

\section{Milk Preparation and Controls}

Raw whole milk was obtained from the Iowa State University Dairy (Ames) bulk tank at or below $4^{\circ} \mathrm{C}$. Milk was immediately transported (drive time less than $10 \mathrm{~min}$; canned milk temperature did not exceed $7^{\circ} \mathrm{C}$ ) to the Iowa State University Center for Crop Utilization Research pilot plant, where it was separated into cream and skim fractions using a centrifugal cream separator (Varidrive Motor, US Electrical Motors Inc., Milford, CT; 1,750 rpm). Skim milk was collected in sterile containers. Approximately $1,600 \mathrm{~mL}$ of raw skim milk was inoculated with $6.07 \pm 0.31 \mathrm{log} \mathrm{cfu} / \mathrm{mL}$ Paenibacillus amylolyticus (H7-0689; Cornell Milk Quality Institute, Ithaca, NY). Milk was refrigerated at $4^{\circ} \mathrm{C}$ for up to 1 $\mathrm{h}$ before processing (heat treatment or sonication). For each lot of milk, inoculated raw spiked control milk was stored in $10-\mathrm{mL}$ sterile plastic snap-top tubes to determine the initial total aerobic count (TAC) in the unprocessed milk for enumeration during up to $8 \mathrm{~d}$ of storage. After only $8 \mathrm{~d}$, spoilage was evident in raw spiked control milk in the form of flocculation and confirmed by TAC exceeding $6 \log \mathrm{cfu} / \mathrm{mL}$.

For each lot of milk, raw spiked control skim milk $(100 \mathrm{~mL})$ was heated in a sanitized stainless steel bowl, covered with aluminum foil, over a hot plate set to $148.9^{\circ} \mathrm{C}$. Milk was stirred with a sanitized rod approximately every $30 \mathrm{~s}$, heated until $72.5 \pm 0.3^{\circ} \mathrm{C}$ (mean \pm $\mathrm{SD}$ ), and held for $15 \mathrm{~s}$. For the pasteurized controls, the milk was immediately divided into $10-\mathrm{mL}$ sterile plastic snap-top tubes. One tube was allocated to be opened for analysis weekly during storage for up to $50 \mathrm{~d}$. Each of the treatments was replicated 3 times over the course of $12 \mathrm{wk}$.

\section{Sonicated Samples}

For each lot of milk, $100 \mathrm{~mL}$ of raw spiked control milk was first pasteurized in the same manner as for the pasteurized control (Figure 1). However, for thermosonicated (T-S) samples, the milk was transferred to a $300-\mathrm{mL}$ capacity glass sonicating rosette cooling cell model 250 (All-Spec Industries Inc., Wilmington, $\mathrm{NC}$ ), submerged in a $73^{\circ} \mathrm{C}$ water bath, and temperature change (typically a decrease of $1^{\circ} \mathrm{C}$; Table 1 ) was recorded. The Branson 2000 (Branson Ultrasonics, Danbury, CT; 2,200 W max power, $20 \mathrm{kHz}$ frequency) 1:8 titanium sonicating horn with $1: 1.5$ booster was lowered 2 to $3 \mathrm{~cm}$ into the milk for sonication under the conditions listed in Table 1. Sample temperatures were recorded at the start of heating, end of heating, start of sonication, and end of sonication.

For cold sonicated (C-S) samples, raw spiked control milk $(100 \mathrm{~mL})$ was transferred to the sonication rosette set in an ice bath. Milk was subjected to the sonicated treatments listed in Table 1. After sonication, each milk sample was transferred to a sanitized stainless steel bowl and pasteurized as previously described. Sample temperatures were recorded at the start of sonication, end of sonication or start of heating, and end of heating. The C-S and T-S milk samples were divided into 10-mL aliquots and stored in sterile snap-top plastic tubes for weekly analysis for up to $50 \mathrm{~d}$. Each of the sonicated treatments was replicated 3 times over the course of 12 wk.

\section{TAC}

The concentration of viable aerobic bacteria in each milk sample was determined by performing TAC. Preliminary work for this project, as well as published research (Blackburn et al., 1996; Casillas-Buenrostro 


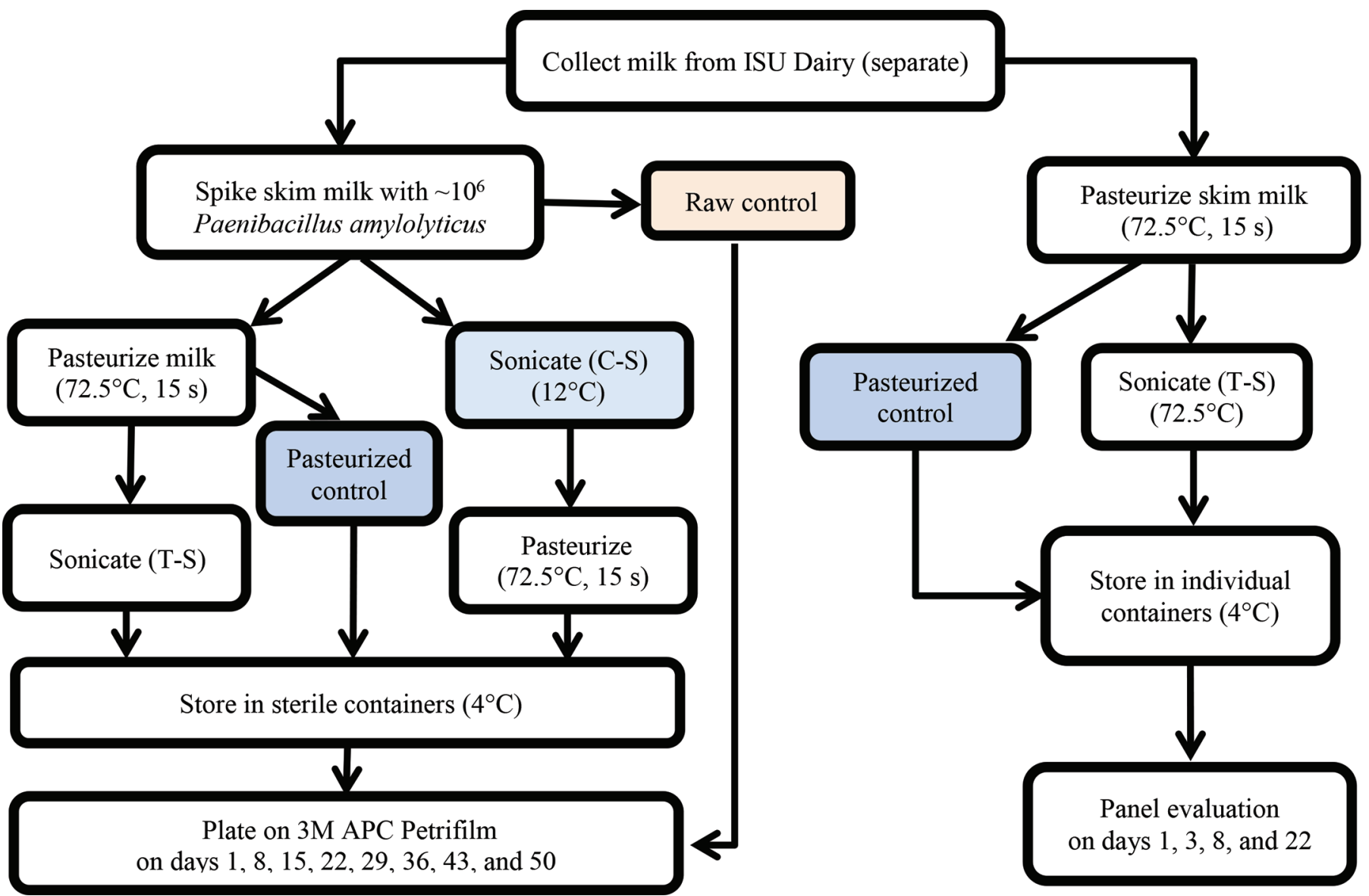

Figure 1. Process for fluid milk collection, sonication, and pasteurization; conducted in triplicate. ISU = Iowa State University; C-S = cold sonicated; T-S = thermosonciated; 3M APC Petrifilm = aerobic plate count Petrifilm (3M, Minneapolis, MN).

Table 1. Treatment conditions for thermosonicated (T-S) and cold sonicated (C-S) skim milk, including statistical analysis of energy density and average temperature before and after treatment for sonication settings

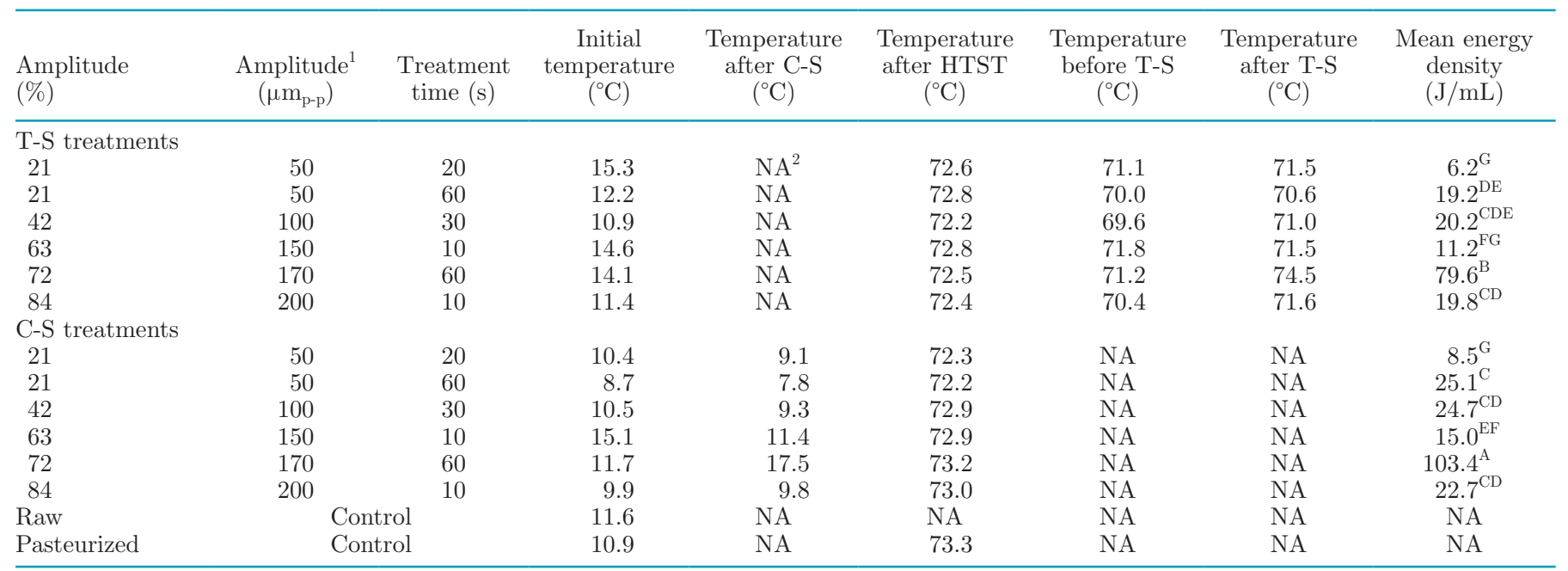

\footnotetext{
$\overline{\mathrm{A}-\mathrm{G}}$ Energy density values with differing letters statistically differ $(P<0.05)$.
}

${ }^{1}$ Where $\mathrm{p}-\mathrm{p}=$ peak-to-peak amplitude.

${ }^{2} \mathrm{NA}=$ not applicable. 
et al., 2012), confirmed that aerobic plate count Petrifilm (3M, Minneapolis, MN) delivers accurate and reproducible results comparable to brain-heart infusion agar pour plates. Colonies on Petrifilm plates were also easier to enumerate due to their bright red appearance. In contrast, pour plates inoculated with undiluted milk samples were difficult to count accurately as a result of the milk's opaque and hazy appearance. Pasteurized control and all sonicated milk samples were plated, undiluted, on d 1 of storage. Raw control dilutions of $10^{-4}$ to $10^{-6}$ were plated on $\mathrm{d} 1$ to confirm presence of live microorganisms and to ensure that the 5-log kill required for pasteurization was obtained (FDA, 2011). Petrifilm plates were aerobically incubated at $32^{\circ} \mathrm{C}$ for enumeration after $96 \mathrm{~h}$. Total aerobic count was expressed in terms of colony-forming units per milliliter and $\log$-transformed $(\log \mathrm{cfu} / \mathrm{mL})$ for readability. Because each set of samples had a different initial bacterial count, expressing results as average log counts does not necessarily represent the effect of the treatment. Therefore, treatment effects are expressed as a difference between the log TAC of the treatment and the log TAC of the corresponding pasteurized control in Table 4.

\section{Sensory Panel Training and Evaluation}

The Institutional Review Board of Iowa State University (ISU) approved recruitment of human subjects for the trained panel. Because milk samples were not legally pasteurized, descriptive sensory analysis was based only on aroma. Nine panelists ( 8 females, 1 male) with prior descriptive analysis experience were recruited from ISU. Group training sessions were held at a round table in the Center for Crops Utilization sensory evaluation facility at ISU for $1 \mathrm{~h}$ per week for 5 wk, with 2 additional individual practice sessions held at the panelists' convenience.

The first training session focused on identifying the typical milk aroma profile expected to be experienced during the study period. Approximately $15 \mathrm{~mL}$ of each sample was transferred into sanitized, opaque screw-top containers (ULINE, Pleasant Prairie, WI), 1 for each panelist. Caps were labeled either with the product identity (early training days) or a 3-digit number (later training days). Panelists agreed that fresh pasteurized skim milk should be free of offensive off-notes, such as sourness or oxidized, and the aroma should be clean, slightly sweet, and have a hint of characteristic milk fat richness. Panelists were acquainted with the aromas of treated milk. The first was raw skim milk heated to $72.5 \pm 0.3^{\circ} \mathrm{C}$ for $15 \mathrm{~s}$. The second was raw skim milk heated identically, then subjected to $200 \mu \mathrm{m}_{\mathrm{p}-\mathrm{p}}$ (approximately $165 \mathrm{~W}$ ) ultrasonication for $60 \mathrm{~s}$ to provide an extreme sonication example. The final sample was raw skim milk that had been collected from the dairy farm bulk tank $3 \mathrm{~d}$ prior. Panelists were guided through generating terms to describe the aromas they detected in these 3 samples. Attributes such as sour, acid, barny, goaty, earthy, dirty, and lacks freshness were attributed to the stored raw milk. The pasteurized sample was deemed cooked, nutty, toasted, sweet aromatic, caramel, eggy, and custardy. The T-S sample shared many of the same descriptors as the pasteurized milk, but it was additionally noted to be burnt, plastic, rubbery, and chemical.

During the second session, all of the terms generated at the first training were compiled and examined. Similar or redundant terms were eliminated, and panelists debated which terms were most appropriate and easily understood. Duplicate milk samples to those smelled at the first training session were evaluated, and panelists reassessed the validity of the terms in question. Ultimately, the terms cooked, rubbery, and lacks freshness were chosen for their lexicon and for more extensive training. Anchors, or references, were selected for each aroma and defined in relation to a $15-\mathrm{cm}$ line scale (Table 2).

The third through fifth training sessions were opportunities for panelists to practice sample evaluation

Table 2. Sensory terms and anchors for aroma attributes of thermosonicated skim milk

\begin{tabular}{lll}
\hline Term & Description & Anchors \\
\hline Cooked & $\begin{array}{l}\text { Characteristic of heated milk, encompassing a range of aromas } \\
\text { from slight sweet or caramel to toasted nuts to custard or egg. }\end{array}$ & $\begin{array}{l}\text { Fairlife }{ }^{1} \text { skim and conventional skim }(50 / 50 \text { mixture }) \\
=\text { score of } 5 \text {; Fairlife skim milk }=\text { score of } 10\end{array}$ \\
Rubbery & $\begin{array}{l}\text { The rubber and chemical aroma of rubber bands. } \\
\text { Rubber bands in skim milk }=\text { score of } 5 \text {; rubber } \\
\text { bands = score of } 15\end{array}$ \\
Lacks freshness & $\begin{array}{l}\text { Milk that is spoiling or has absorbed unpleasant off-aromas } \\
\text { from the milking environment. Described with terms such as } \\
\text { acid or sour, barny, stale, dirty, or unclean. }\end{array}$ & $\begin{array}{l}\text { Raw milk stored } 3 \mathrm{~d}=\text { score of 5; raw milk stored } 8 \\
\mathrm{~d}=\text { score of } 15\end{array}$ \\
\hline
\end{tabular}

${ }^{1}$ Fairlife LLC (Chicago, IL.) 
in a group setting. Panelists sniffed samples and discussed their observations until consensus was reached. Two additional 30-min individual sniffing sessions were held without discussion to test within- and betweenpanelists consistency.

To prepare for sensory evaluation, approximately $15 \mathrm{~mL}$ of each sample was transferred into sanitized, opaque screw-top containers (ULINE), 1 for each panelist and each day of evaluation (9 panelists; d 1, 3, 8, and 21 of storage). Each treatment was replicated 3 times. Panelists were given no more than 6 randomly presented samples (pasteurized controls or T-S samples) at each evaluation session to minimize fatigue. No C-S samples were evaluated because, at the time of the sensory study, the C-S study had not been conceived of yet; by the time the C-S study was conducted, some panelists had graduated. Similar to Vijayakumar et al. (2015), panelists were asked to place a vertical mark on a $15-\mathrm{cm}$ line indicating the intensity of the cooked, rubbery, and lacks freshness attributes they detected in the sample. The distance from zero to the marked segment was measured in centimeters.

\section{Statistical Analysis}

Energy density differences and sensory data were analyzed using JMP (JMP Pro 11; SAS Institute Inc., Cary, NC). A one-way ANOVA was performed to analyze both the differences in mean sensory scores for each aroma between treatments on each day and for the difference between days for each treatment using Tukey-Kramer adjustment for multiple comparisons and significance of $\alpha<0.05$ using JMP (Version 11 Pro). Analysis of the mean log difference (MLD) between the TAC of the T-S or C-S treatment and the TAC of the pasteurized control was performed by IBM SPSS Statistics (V.24, IBM Corp., Armonk, NY). Mean values of MLD in each treatment and storage day were compared by $t$-test and ANOVA with least significance difference at $\alpha<0.05$. Days 36 through 50 were not included in this model because of spoilage or data censoring from estimated counts.

\section{RESULTS AND DISCUSSION}

\section{Sonicated Samples}

The treatment conditions for C-S and T-S milk, along with mean initial and final temperatures, are summarized in Table 1. The values before and after sonication demonstrated that sonication generated little to no heat. Because sonication was performed in temperature-controlled situations (i.e., ice bath for C-S; hot water bath for T-S), the temperature changes of all milk samples before and after treatment were less than $6^{\circ} \mathrm{C}$ for C-S and less than $4^{\circ} \mathrm{C}$ for T-S. Thus, treatment differences in the present study were a result of the sound energy and subsequent cavitation and not of a bulk temperature increase.

Table 1 also summarizes the statistical analysis of mean energy density values for treatments. Energy density was calculated according to Zisu et al. (2013) by dividing the joules of energy delivered to the sample by the sample volume. Energy density allows for a more direct comparison between treatments in terms of intensity rather than simply expressing ultrasound treatments in terms of amplitude, wattage, or frequency. Despite initially selecting diverse ultrasound treatments based on amplitude and duration, many treatments were very similar energetically. Statistical analysis of the energy density for all treatments reveals that, in general, more energy was transferred to the C-S samples than the T-S samples for a given treatment (Table 1). This is in agreement with literature; prior research reported that as the temperature of a fluid increases, so does its vapor pressure, leading to less violent cavitation and therefore less energy transfer (Herceg et al., 2012; Juliano et al., 2014). The difference in energy density between the C-S and T-S samples was not significant for treatments of $50 \mu \mathrm{m}_{\mathrm{p}-\mathrm{p}} / 20 \mathrm{~s}, 150 \mu \mathrm{m}_{\mathrm{p}-\mathrm{p}} / 10 \mathrm{~s}$, and $200 \mu \mathrm{m}_{\mathrm{p}-\mathrm{p}} / 10$ $\mathrm{s}$, but C-S had a significantly higher energy density compared with T-S for the $170 \mu \mathrm{m}_{\mathrm{p}-\mathrm{p}} / 60 \mathrm{~s}, 50 \mu \mathrm{m}_{\mathrm{p}-\mathrm{p}} / 60$ $\mathrm{s}$, and $100 \mu \mathrm{m}_{\mathrm{p}-\mathrm{p}} / 30 \mathrm{~s}$ treatments (Table 1 ). The C-S 50 $\mu \mathrm{m}_{\mathrm{p}-\mathrm{p}} / 60 \mathrm{~s}, 100 \mu \mathrm{m}_{\mathrm{p}-\mathrm{p}} / 30 \mathrm{~s}$, and $200 \mu \mathrm{m}_{\mathrm{p}-\mathrm{p}} / 10 \mathrm{~s}$, along with the T-S $200 \mu \mathrm{m}_{\mathrm{p}-\mathrm{p}} / 10 \mathrm{~s}$ and $100 \mu \mathrm{m}_{\mathrm{p}-\mathrm{p}} / 30 \mathrm{~s}$ treatments, all delivered the same amount of energy, ranging from an average of 20.1 to $25.1 \mathrm{~J} / \mathrm{mL}$ (Table 1 ). The C-S treatment at $170 \mu \mathrm{m}_{\mathrm{p}-\mathrm{p}} / 60 \mathrm{~s}$ was the most energy dense, at $103.4 \mathrm{~J} / \mathrm{mL}$. The general energy density of T-S treatments of the same time and amplitude were significantly lower than C-S, averaging $79.6 \mathrm{~J} / \mathrm{mL}$. The lowest energy density was delivered by the treatment of $50 \mu \mathrm{m}_{\mathrm{p}-\mathrm{p}} / 20 \mathrm{~s}$, which did not differ significantly between C-S and T-S (Table 1).

As the majority of treatments were not significantly different from each other in terms of energy density, any differences in TAC between such energetically identical treatments may be attributed to temperature (C-S vs. T-S), amplitude, or treatment time, rather than the amount of energy delivered. Christen et al. (2012) theorized that exposure time - not amount of ultrasonic power - was the most important factor for inactivation of Escherichia coli. Marchesini et al. (2015) also found that ultrasound duration was significant in relation to killing E. coli, Pseudomonas fluorescens, and Staphylococcus aureus. Other researchers have found 
that amplitude is important because of an increase in area being affected by sonic energy as amplitude increases (Khanal et al., 2014a).

\section{TAC}

The mean log TAC for all treatments, weekly through d 50 of storage, are included in Table 3 . Raw spiked control milk (data not shown) was only plated to $\mathrm{d} 8$, when spoilage became evident. A sample was judged spoiled when it reached $6 \log \mathrm{cfu} / \mathrm{mL}$ or when protein coagulation (flocculation) was visible in the sample container (Fromm and Boor, 2004). Visibly spoiled samples were not enumerated. On d 1, the pasteurized control had a mean TAC of $1.48 \pm 0.13 \mathrm{log} \mathrm{cfu} / \mathrm{mL}$, and all C-S and T-S treatments ranged between 1.39 to $1.79 \mathrm{log}$ $\mathrm{cfu} / \mathrm{mL}$. These findings demonstrate how neither C-S nor T-S meaningfully modified initial counts compared with standard pasteurized control. A week later, mean counts for C-S and T-S milk ranged from 1.50 to 1.89 $\log \mathrm{cfu} / \mathrm{mL}$, which were similar to pasteurized control $(1.49 \pm 0.12 \log \mathrm{cfu} / \mathrm{mL})$. By d 15, TAC of C-S and T-S milk ranged from as low as 1.32 to $3.00 \mathrm{log} \mathrm{cfu} /$ $\mathrm{mL}$, whereas pasteurized control remained similar to $\mathrm{d}$ 1 counts $(1.51 \pm 0.18 \log \mathrm{cfu} / \mathrm{mL})$.

Day 22 is an important time point because it is the typical shelf life of pasteurized milk. By d 22, TAC for all C-S and T-S treatments, as well as the pasteurized control, were still less than $6 \log \mathrm{cfu} / \mathrm{mL}$, and none showed evidence of flocculation. However, several treatments showed mean $\log$ TAC approaching 4 to $5 \log$ $\mathrm{cfu} / \mathrm{mL}$, which may have tasted spoiled to discerning consumers. The T-S samples treated at $50 \mu \mathrm{m}_{\mathrm{p}-\mathrm{p}} / 20$ $\mathrm{s}, 100 \mu \mathrm{m}_{\mathrm{p}-\mathrm{p}} / 30 \mathrm{~s}$, and $170 \mu \mathrm{m}_{\mathrm{p}-\mathrm{p}} / 60 \mathrm{~s}$ had mean TAC of $4.65 \pm 0.12,5.09 \pm 0.82$, and $4.88 \pm 0.38 \log \mathrm{cfu} /$ $\mathrm{mL}$, respectively. The $\mathrm{C}-\mathrm{S}$ treatments maintained lower TAC counts, ranging from a low of $1.34 \pm 0.13 \mathrm{log} \mathrm{cfu} /$ $\mathrm{mL}$ for $200 \mu \mathrm{m}_{\mathrm{p}-\mathrm{p}} / 10 \mathrm{~s}$, to a high of $2.86 \pm 0.02 \log \mathrm{cfu} /$ $\mathrm{mL}$ for $170 \mu \mathrm{m}_{\mathrm{p}-\mathrm{p}} / 60 \mathrm{~s}$. The lowest C-S mean TAC was still higher than the pasteurized control, at $1.20 \pm 0.10$ $\log \mathrm{cfu} / \mathrm{mL}$.

By d 29, bacterial growth patterns became unpredictable and mean TAC had to be estimated because bacterial growth either exceeded or was lower than the selected dilution level plated (Table 3). Many replicates experienced a large jump in TAC, greater than the week-to-week change seen earlier in shelf life, suggesting a bloom of psychrotrophic organisms in the final week of storage. This was particularly evident in T-S samples, which all exceeded $4.30 \mathrm{log} \mathrm{cfu} / \mathrm{mL}$ by $\mathrm{d} 36$ and visibly spoiled by d 43 . In contrast, all but $1 \mathrm{C}-\mathrm{S}$ sample $\left(150 \mu \mathrm{m}_{\mathrm{p}-\mathrm{p}} / 10 \mathrm{~s}\right)$ had counts lower than 3.00 $\log \mathrm{cfu} / \mathrm{mL}$ through d 50 . The pasteurized controls maintained counts below $2.00 \log \mathrm{cfu} / \mathrm{mL}$ through d

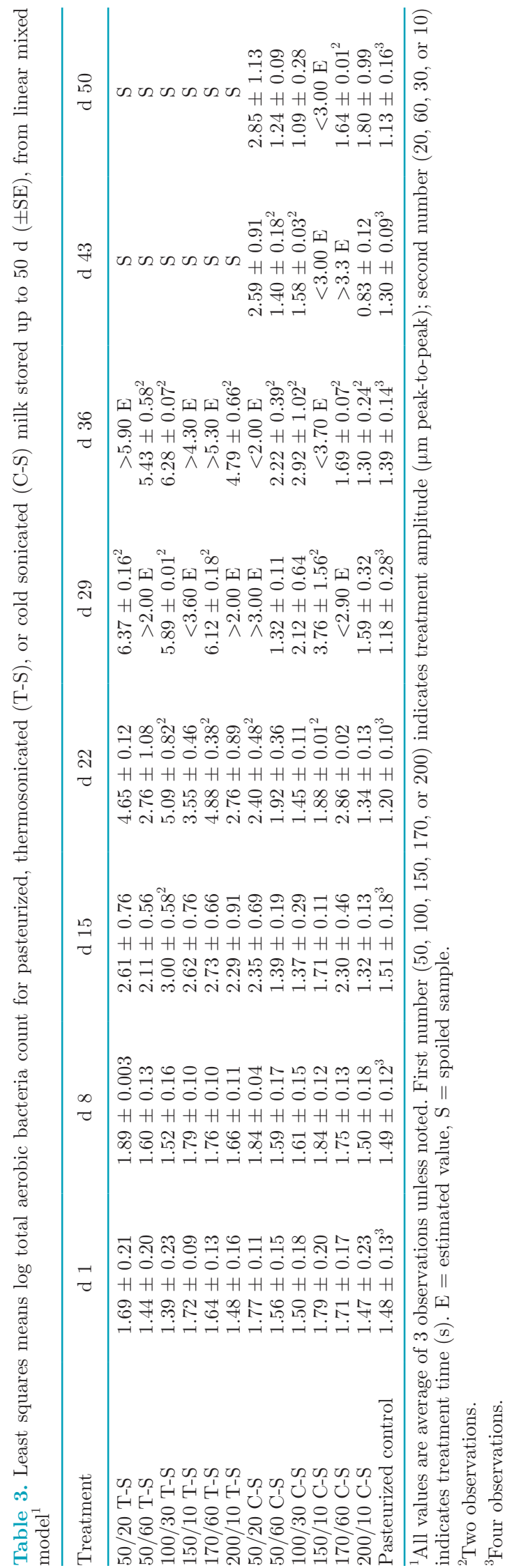

Journal of Dairy Science Vol. 102 No. 5, 2019 
50 (Table 3), demonstrating the effectiveness of our laboratory pasteurization conditions.

\section{MLD for TAC}

Milk naturally contains a variable amount of bacteria based on the cleanliness of the milking conditions, dairy workers, sanitation, and storage conditions (Huck et al., 2008; Ranieri and Boor, 2009). Therefore, a simple mean obtained from replications of treatments on milk with different initial bacterial counts does not accurately represent treatment effects. Because experiments were conducted over $12 \mathrm{wk}$ using a different batch of milk each week, and each batch of milk had its own set of controls, data were transformed in relation to the pasteurized control corresponding to the batch of milk from which that treatment originated. In Table 4 , data from d 1 to 22 are presented as the MLD between the treatment TAC and the TAC of the pasteurized control from the same milk batch. This procedure allows control for milk batch as a source of random variation. A negative MLD value indicates that the treatment had a lower TAC than the pasteurized control, meaning that the sonicated treatment was more effective than pasteurization alone; positive numbers mean the opposite.

In all cases through d 15 (except 1), MLD were within $1 \mathrm{log}$ of respective pasteurized controls. Additionally, only $1 \mathrm{~T}-\mathrm{S}$ treatment $\left(100 \mu \mathrm{m}_{\mathrm{p}-\mathrm{p}} / 30 \mathrm{~s} ; \mathrm{d} 1\right)$ and $5 \mathrm{C}-\mathrm{S}$ treatments, $\left(50 \mu \mathrm{m}_{\mathrm{p}-\mathrm{p}} / 60 \mathrm{~s}, 100 \mu \mathrm{m}_{\mathrm{p}-\mathrm{p}} / 30\right.$ $\mathrm{s}, 150 \mu \mathrm{m}_{\mathrm{p}-\mathrm{p}} / 10 \mathrm{~s}, 170 \mu \mathrm{m}_{\mathrm{p}-\mathrm{p}} / 60 \mathrm{~s}$, and $200 \mu \mathrm{m}_{\mathrm{p}-\mathrm{p}} / 10 \mathrm{~s}$; d 15) had a negative MLD. Every other C-S and T-S treatment yielded milk with positive MLD and higher counts than their respective pasteurized controls. These results confirm that neither $\mathrm{C}-\mathrm{S}$ nor T-S were more effective than pasteurization at reducing milk TAC or extending milk microbial shelf life (Table 4).

Statistical analysis revealed that, on $\mathrm{d} 22$, the MLD from control of all T-S and 1 C-S sample were significantly higher than the MLD from control of almost all other samples on previous days $(P<0.05)$. One reason for this phenomenon can be explained by the findings of Ranieri et al. (2009). Although their research did not focus on ultrasound technology, those authors found that higher pasteurization temperatures $\left(85.2^{\circ} \mathrm{C}\right.$ instead of $72.9^{\circ} \mathrm{C}$ ) led to increased sporulation and eventual cell growth among contaminating gram-positive bacteria during subsequent storage. Gram-negative microorganisms, such as E. coli, have a more flexible cell membrane compared with the more rigid wall of grampositive bacteria. It has been observed that ultrasound is more effective in destroying gram-negative bacteria than gram-positive bacteria (Gao et al., 2014). Our T-S samples were not pasteurized at a higher temperature, but some samples experienced a small bulk temperature increase or, more importantly, localized extreme temperature resulting from cavitation. The localized stress potentially induced conditions for sporulation and later germination. Khanal et al. (2014b) applied this theory to ultrasonication and found similar results, as the treatments simply led to sporulation rather than destroying cells.

Thermal treatments such as pasteurization and UHT are capable of killing most spoilage and pathogenic bacteria, but they show a limited effectiveness on thermoduric spore-formers and their spores (Lewis and Deeth, 2009). Sporulation is a mechanism of survival for bacterial cells in response to adverse conditions, including stress and starvation. Spores form as an end-product

Table 4. One-way ANOVA of mean log difference (MLD) from pasteurized control for total aerobic counts of milk treated with ultrasound before (cold sonication; C-S) or after (thermosonication; T-S) pasteurization $( \pm \mathrm{SE}$ ), for milk stored 1, 8, 15 and $22 \mathrm{~d}$

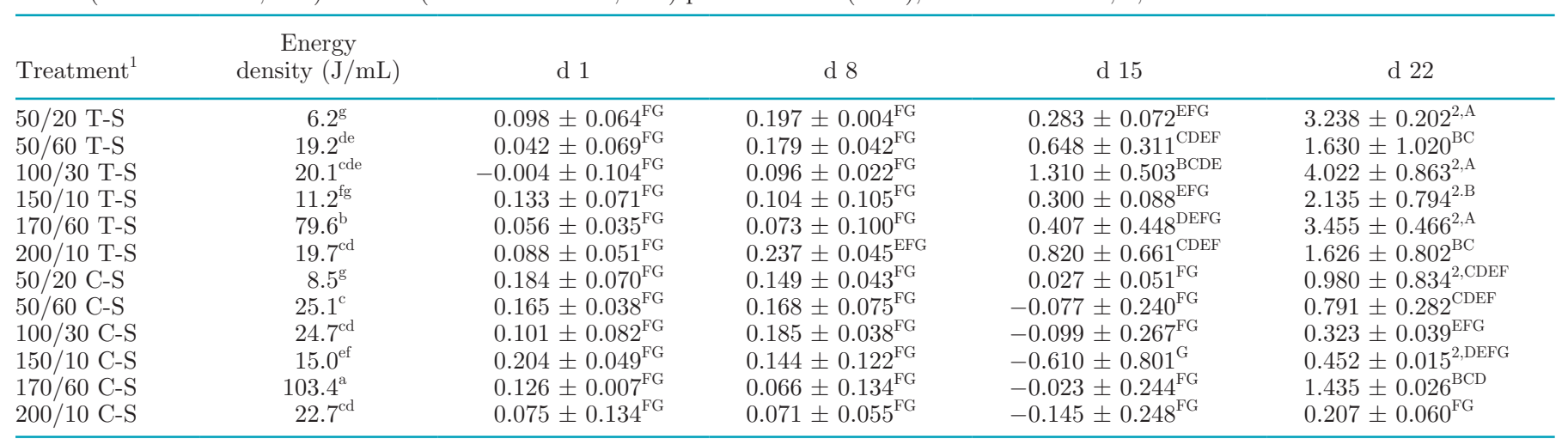

${ }^{\mathrm{a}-\mathrm{g}}$ Energy density values with differing letters statistically differ $(P<0.05)$.

${ }^{\mathrm{A}-\mathrm{G}}$ Mean $\log$ differences with differing letters statistically differ $(P<0.05)$.

${ }^{1}$ First number $(50,100,150,170$, or 200$)$ indicates treatment amplitude ( $\mu$ m peak-to-peak); second number $(20,60,30$, or 10) indicates treatment time (s).

${ }^{2}$ Two observations. 
of the sporulation process, which results in mother cell lysis to release spores (Setlow and Johnson, 2012). Multiple layers are then formed around the spore, between their inner membrane and outer membrane, which include a cell wall, a thick peptidoglycan cortex with a complex protein coating (Setlow and Johnson, 2012). Beaman and Gerhardt (1986) evaluated the factors affecting spore heat resistance and found that thermal adaptation can affect spore resistance by reducing the water content and increasing wet density and by mineralization, where calcium remineralized protoplasts were drier and, hence, were more heat resistant (Beaman et al., 1982; Beaman and Gerhardt, 1986). Spores can be converted under adverse and stressful conditions and then resist severe heat treatments, radiations, chemicals, and high pressure, which make them capable of surviving under unfavorable conditions (Setlow, 2006; Henriques and Moran, 2007; Burgess et al., 2010). Once the conditions become favorable, spores convert themselves to vegetative cells by activating themselves first, then germinating, and multiplying (Setlow, 2003).

The present findings further substantiate the observation that a bloom of psychrotrophic bacteria occurred in T-S samples between d 15 and 22. These results lead us to believe that, although pasteurization killed some cells, it also injured some cells and induced spore formation of yet other cells. Subsequent ultrasonication, we hypothesized, caused germination of spores (some of those acquired from the environment and some of those added to the milk), which enabled earlier outgrowth of vegetative cells in the milk between $\mathrm{d} 15$ and 22. Although none of the C-S or T-S treatments could be considered effective compared with the pasteurized controls on d 1 through 22, the significant differences between C-S and T-S treatments in their effect on TAC help explain the microbiology. Our initial research was designed to only look at T-S. However, after seeing the T-S results, we designed the C-S experiments, hypothesizing that ultrasound could be used to germinate spores or damage vegetative cells enough to make them vulnerable to heat, and that subsequent pasteurization would kill them. Unfortunately, the results obtained in our study only partially support that hypothesis. If fully supported, C-S would have had a greater effect on reducing TAC compared with pasteurization; C-S was more effective than T-S, but not better than pasteurization alone (Tables 3 and 4 ).

To isolate the effect of energy density in the present study, a regression of MLD on energy density $(\mathrm{J} / \mathrm{mL})$ was conducted for C-S and T-S (data not presented; energy density values are included in Table 4). Only $10 \%$ of the variability in T-S MLD from pasteurized control could be explained by the treatment energy density. For C-S MLD from pasteurized control, $49 \%$ of the variability could be explained by the energy density. For both C-S and T-S, the least energy-dense treatments $\left(50 \mu \mathrm{m}_{\mathrm{p}-\mathrm{p}} / 20 \mathrm{~s}\right)$ were not the least effective treatments, but the most energy-dense treatments (170 $\mu \mathrm{m}_{\mathrm{p}-\mathrm{p}} / 60 \mathrm{~s}$ ) were among the least effective treatments (least effective of all C-S and second least effective for T-S). Khanal et al. (2014a) reported that an increase of amplitude from 91.2 to $114 \mu \mathrm{m}_{\mathrm{p}-\mathrm{p}}$ did not result in a significant effect in spore inactivation. This, coupled with our findings, indicates that energy density alone is not directly related to the effect of ultrasonication on cells. It is likely that amplitude, time, and energy density are all important factors to consider when choosing ultrasonication settings.

It is possible that more time is needed between the sonication and heating steps, or that more severe sonication or pasteurization conditions are needed. Under both C-S and T-S treatments conducted in the present study, it is also possible that thermophilic microorganisms such as Bacillus sporothermodurans or Geobacillus stearothermophilus were present, stimulated by ultrasound, and survived pasteurization (Casillas-Buenrostro et al., 2012). Because no isolation of microorganisms or biochemical tests were done in our study, it is impossible to conclude whether gram-positive spore-forming bacteria were responsible for the increase in TAC and observed milk spoilage. Gram-negative bacteria present in raw milk may have outcompeted Paenibacillus or Bacillus present because of their faster growth (Ranieri and Boor, 2009). In future studies, the identity of the microorganisms presented before and after ultrasonication should be determined to illuminate the best method for treating the specific type of cell or spore.

\section{Sensory Evaluation}

The trained panelists' mean scores for cooked, rubbery, and lacks freshness aromas are displayed for each treatment (Table 5). Mean ratings of cooked aroma were low (did not exceed 3.8 on a 15 -cm line scale) throughout storage, and we found no significant differences between the panelists' ratings among treatments or across days $(P>0.05)$. Although the cavitation heat and pressure generated by ultrasound energy itself is capable of denaturing whey protein and producing sulfhydryl aromas (Juliano et al., 2014), the intensity of the cooked aroma was neither extreme (above 10.0 on 15 -cm line scale) nor intensified by the T-S treatments selected in the present work.

Similar to the cooked attribute, we observed no significant differences among mean scores for the intensity of lacks freshness aroma among samples (Table 5). Ad- 
Table 5. Mean trained panelist ratings $(\mathrm{n}=9 ; 15$-cm line scale $\pm \mathrm{SD})$ of cooked, lacks freshness, and rubbery aroma attributes of skim milk subjected to thermosonication or pasteurization

\begin{tabular}{|c|c|c|c|c|}
\hline $\begin{array}{l}\text { Thermosonicated } \\
\text { milk treatments }\end{array}$ & d 1 & d 3 & d 8 & d 21 \\
\hline \multicolumn{5}{|l|}{ Cooked } \\
\hline $170 / 60$ & $3.8 \pm 3.8^{\mathrm{A}}$ & $3.4 \pm 2.6^{\mathrm{A}}$ & $2.6 \pm 2.3^{\mathrm{A}}$ & $3.3 \pm 2.7^{\mathrm{A}}$ \\
\hline $200 / 10$ & $2.7 \pm 2.4^{\mathrm{A}}$ & $3.1 \pm 2.7^{\mathrm{A}}$ & $3.2 \pm 2.6^{\mathrm{A}}$ & $2.7 \pm 3.1^{\mathrm{A}}$ \\
\hline Pasteurized control & $2.4 \pm 2.6^{\mathrm{A}}$ & $3.3 \pm 2.6^{\mathrm{A}}$ & $2.3 \pm 2.3^{\mathrm{A}}$ & $2.4 \pm 2.4^{\mathrm{A}}$ \\
\hline \multicolumn{5}{|l|}{ Lacks freshness } \\
\hline $170 / 60$ & $0.8 \pm 1.6^{\mathrm{A}}$ & $0.4 \pm 0.7^{\mathrm{A}}$ & $1.5 \pm 2.0^{\mathrm{A}}$ & $1.3 \pm 2.4^{\mathrm{A}}$ \\
\hline $200 / 10$ & $1.1 \pm 2.1^{\mathrm{A}}$ & $0.9 \pm 1.7^{\mathrm{A}}$ & $1.5 \pm 2.4^{\mathrm{A}}$ & $1.9 \pm 2.2^{\mathrm{A}}$ \\
\hline Pasteurized control & $1.8 \pm 2.6^{\mathrm{A}}$ & $1.1 \pm 1.3^{\mathrm{A}}$ & $1.5 \pm 2.0^{\mathrm{A}}$ & $1.6 \pm 2.1^{\mathrm{A}}$ \\
\hline \multicolumn{5}{|l|}{ Rubbery } \\
\hline $170 / 60$ & $4.5 \pm 4.9^{\mathrm{A}}$ & $3.2 \pm 4.1^{\mathrm{AB}}$ & $2.0 \pm 3.0^{\mathrm{AB}}$ & $0.8 \pm 1.8^{\mathrm{B}}$ \\
\hline $200 / 10$ & $1.3 \pm 2.0^{\mathrm{B}}$ & $1.2 \pm 2.3^{\mathrm{ABC}}$ & $0.9 \pm 1.8^{\mathrm{B}}$ & $1.0 \pm 1.9^{\mathrm{B}}$ \\
\hline Pasteurized control & $2.1 \pm 3.1^{\mathrm{AB}}$ & $2.0 \pm 3.1^{\mathrm{AB}}$ & $1.9 \pm 2.9^{\mathrm{B}}$ & $1.6 \pm 2.6^{\mathrm{B}}$ \\
\hline
\end{tabular}

ditionally, the amount of lacks freshness aroma did not significantly increase during refrigerated storage $(21 \mathrm{~d}$; $P>0.05$ ). The low mean scores (below 2.0 on 15 -cm line scale) demonstrate that the pasteurization process and the T-S treatments selected in the present study enabled milk to smell fresh for up to $21 \mathrm{~d}$, which is the typical shelf life of pasteurized milk. The low TAC up to $22 \mathrm{~d}$ support the absence of lacks freshness aromas from bacterial sources.

Unlike the other attributes in question, the rubbery aroma did vary significantly among treatments (Table $5)$. One day post-treatment, the $170 \mu \mathrm{m}_{\mathrm{p}-\mathrm{p}} / 60 \mathrm{~s}$ milk yielded a mean score of 4.5 out of 15 . This did not significantly differ from the score of the pasteurized control samples (2.1) but was significantly higher than the mean score for the $200 \mu \mathrm{m}_{\mathrm{p}-\mathrm{p}} / 10 \mathrm{~s}$ sample $(1.3 ; P$ $<0.05)$. The rubbery aroma in all samples dissipated over time: for the pasteurized control it took until d 8 , whereas for the $170 \mu \mathrm{m}_{\mathrm{p}-\mathrm{p}} / 60 \mathrm{~s}$ it took until d 21. Additionally, it should be noted that the rubbery aroma never exceeded 5 on a $15-\mathrm{cm}$ line scale, suggesting that the mild treatments selected for the present study may be applicable to commercial applications from a sensory standpoint. The aromas produced by T-S are distinct in origin from traditional cooked aromas, but, as the results of the present study demonstrate, they are not easily distinguished by a trained sensory panel. Standard deviations for rubbery were greater than the average rubbery rating for all samples over all evaluation days. Despite training, some panelists were more sensitive to the rubbery aroma than others. Some panelists identified strong cooked aromas as rubbery or vice versa; however, statistical analysis determined that no one panelist skewed data than any other, so no data were discarded.
Mean rubbery aroma scores were similar to but slightly lower than those observed by Vijayakumar et al. (2015), who used similar ultrasonic amplitude conditions but longer treatment times (up to $3 \mathrm{~min}$ ). Additionally, the present work demonstrates that the rubbery aroma dissipated relatively rapidly during refrigerated storage. As short-duration T-S milk may not be distinguishable from pasteurized milk by the time that consumers receive the milk (generally within $3 \mathrm{~d}$ of processing), short-duration T-S may be appropriate for industry applications from a sensory standpoint. In contrast to pasteurization, ultrasound energy produces off-flavors resulting from radical or cavitation-induced heat damage to milk components, specifically fat (Juliano et al., 2014). Our experiment used high-power, low-frequency sonication $(20 \mathrm{kHz})$; at this frequency, the size of cavitation bubbles formed in a fluid such as milk are larger and less numerous than what would be present at a higher frequency. The number of free radicals generated is correlated with both the number of bubbles and the violence of their collapse. Large bubbles collapse more violently than small bubbles, but the end result is fewer free radicals (Marchesini et al., 2012; Juliano et al., 2014), indicating that the rubbery aroma in the ultrasonicated samples may originate from heat-induced oxidation of lipids into volatile compounds instead of a radical mechanism.

Whereas the sensory effects of T-S on milk may not limit the commercial feasibility of cold sonication or thermosonication, conditions that differ from those used in the present study should be considered in future studies to ensure extended microbial shelf life. Future research should focus on standardizing the way ultrasound treatment conditions are reported as well as examining the effect of temperature and am- 
plitude on bacterial counts and sensory quality. Heat and ultrasound have been shown to have a complicated synergistic or antagonistic relationship depending on the study conditions, and more work should be done to ameliorate the consistency issues in ultrasound research of fluid milk.

Although the majority of ultrasound treatments are only proven in the laboratory, ultrasound has numerous applications in the dairy industry, ranging from microbial reduction to tailoring ingredient functionality (Zisu and Chandrapala, 2015). As ultrasonic processing is a relatively new field of endeavor in dairy research, the availability of industrial scale or even pilot-scale equipment is still quite limited (Ashokkumar et al., 2011). Currently, the best opportunities for adoption of this technology would seem to be as an adjunct process in an existing processing line of the dairy industry. Ultrasound has not currently been used to widespread acceptance in fluid milk for processing or preservation, in part because of the limited knowledge on the effects upon shelf-limiting enzymes, sensory and other quality parameters (Ashokkumar et al., 2011; Zisu and Chandrapala, 2015).

If ultrasound is to be applied to a dairy processing operation, it will be important to consider all of the effects of the treatment. Milk is a complex fluid and its components are subject to damage from acoustic cavitation. The possibilities of lipid oxidation, whey denaturation, reduction of milk fat globule size, and changes to the casein micelle structure must all be considered. Some of these changes may be beneficial or desired. However, except for homogenization effects, physical changes may not be desirable in fluid milk intended for direct consumption, where consumers crave a clean-tasting, refreshing beverage with characteristic fresh dairy flavor. Further research on ultrasound treatment of fluid dairy milk is needed to illuminate the line between improved functionality or stability and sensory quality. Although we evaluated skim milk, skim milk is not entirely fat-free. Residual fat tends to be more susceptible to radical reactions because it may not be contained within intact milkfat globules (Frankel, 1980; Walstra et al., 1999). Additionally, indigenous milk lipases or those produced by contaminating psychrotolerant bacteria can contribute to volatile formation during refrigerated shelf life, exacerbating the off-flavor problem (Juliano et al., 2014). For the most sensitive of consumers, the results of our study demonstrate that even a mild T-S treatment of $72 \%$ amplitude (170 $\mu \mathrm{m}_{\mathrm{p}-\mathrm{p}} / 60 \mathrm{~s}$ ) can cause a rubbery aroma, which might be objectionable during early shelf life. Although the rubbery odor faded significantly within $21 \mathrm{~d}$, the most sensitive consumer might perceive a rubbery-smelling product, which could inhibit future purchasing.

\section{CONCLUSIONS}

Dairy processing with high-power, low-frequency ultrasound is an emerging field of research, and many complexities have yet to be elucidated. Some studies have shown that ultrasound is capable of increased bacterial kill compared with pasteurization alone, but may induce undesirable flavors and aromas under certain treatment conditions. The mild treatments selected for the present study may be applicable to commercial applications from a sensory standpoint, as a low-level objectionable rubbery aroma dissipated very quickly. However, bacteria counts in milk treated with thermosonication and cold sonication were significantly higher than pasteurized control milk spiked with Paenibacillus amylolyticus throughout all $22 \mathrm{~d}$ of storage, particularly for T-S samples. This research demonstrated that thermosonication induces vegetative cells of anaerobic spore-forming bacteria to form heat-resistant spores, enabling higher rates of subsequent spoilage than standard pasteurization. Integration of T-S with HTST, under the conditions of this study, is not a feasible means of extending milk shelf life. Cold sonication may be an appropriate method, but more research is needed to optimize the conditions and understand the effect of C-S and subsequent heating, including the identity of surviving microorganisms, to ensure effectiveness at eliminating bacteria and extending the shelf life of fluid milk.

\section{ACKNOWLEDGMENTS}

This research was funded by the dairy farmers of Iowa, through the Midwest Dairy (St. Paul, MN). We are grateful for the assistance of Cindu Annandarajah and Samantha Lobb (Iowa State University) in conducting the laboratory work, and acknowledge the time and expertise provided by our trained panelists. Special thanks are extended to the Iowa State University Center for Crop Utilization Research (CCUR, Ames, IA) for providing space, and to Branson Ultrasonics (Danbury, CT) for providing the ultrasonics equipment. Appreciation is also extended to David Grewell, previously in the department of Agricultural and Biological Engineering at ISU, and currently chair of the department of Industrial and Manufacturing Engineering at North Dakota State University (Fargo), who served as an advisor to Lily Benner during her MS degree program. This article is a product of the Iowa Agriculture 
and Home Economics Experiment Station, Ames, Iowa. Project No. IOW04002 is sponsored by Hatch Act and State of Iowa funds.

\section{REFERENCES}

Ashokkumar, M. 2011. The characterization of acoustic cavitation bubbles: An overview. Ultrason. Sonochem. 18:864-872.

Ashokkumar, M., R. Bhaskaracharya, S. Kentish, J. Lee, M. Palmer, and B. Zisu. 2010. The ultrasonic processing of dairy products: An overview. Dairy Sci. Technol. 90:147-168.

Beaman, T. C., J. Greenamyre, T. Corner, H. Pankratz, and P. Gerhardt. 1982. Bacterial spore heat resistance correlated with water content, wet density, and protoplast/sporoplast volume ratio. J. Bacteriol. 150:870-877.

Beaman, T. C., and P. Gerhardt. 1986. Heat resistance of bacterial spores correlated with protoplast dehydration, mineralization, and thermal adaptation. Appl. Environ. Microbiol. 52:1242-1246.

Bendicho, S., A. R. Marselles-Fontanet, G. V. Barbosa-Canovas, and O. Martin-Belloso. 2005. High intensity pulsed electric fields and heat treatments applied to a protease from Bacillus subtilis. A comparison study of multiple systems. J. Food Eng. 69:317-323.

Bilbao-Sainz, C., F. L. Younce, B. Rasco, and S. Clark. 2009. Protease stability in bovine milk under combined thermal-high hydrostatic pressure treatment. Innov. Food Sci. Emerg. Technol. 10:314-320.

Blackburn. C. W., C. L. Baylis, and S. B. Petitt. 1996. Evaluation of Petrifilm methods for enumeration of aerobic flora and coliforms in a wide range of foods. Lett. Appl. Microbiol. 22:137-140.

Boor, K. J. 2001. Fluid dairy product quality and safety: Looking to the future. J. Dairy Sci. 84:1-11.

Borda, D., S. C. Indrawati, C. Smout, A. Van Loey, and M. Hendrickx. 2004. High pressure thermal inactivation kinetics of a plasmin system. J. Dairy Sci. 87:2351-2358.

Burgess, S. A., D. Lindsay, and S. H. Flint. 2010. Thermophilic bacilli and their importance in dairy processing. Int. J. Food Microbiol. 144:215-225.

Bus, A. E., and A. Worsley. 2003. Consumers' sensory and nutritional perceptions of three types of milk. Public Health Nutr. 6:201-208.

Butz, P., and B. Tauscher. 2002. Emerging technologies: Chemical aspects. Food Res. Int. 35:279-284.

Cameron, M., L. D. McMaster, and T. J. Britz. 2008. Electron microscopic analysis of dairy microbes inactivated by ultrasound Ultrason. Sonochem. 15:960-964.

Cameron, M., L. D. McMaster, and T. J. Britz. 2009. Impact of ultrasound on dairy spoilage microbes and milk components. Dairy Sci Technol. 89:83-98.

Casillas-Buenrostro, R. M., N. L. Heredia, D. L. Benesh, and S. Garcia. 2012. Efficacy of 3M Petrifilm aerobic count plates for enumerating Bacillus sporothermodurans and Geobacillus stearothermophilus in UHT milk. Int. Dairy J. 25:147-149.

Chouliara, E., K. G. Georgogianni, N. Kanellopoulou, and M. G. Kontominas. 2010. Effect of ultrasonication on microbiological, chemical, and sensory properties of raw, thermized and pasteurized milk. Int. Dairy J. 20:307-313.

Christen, L., C. Tat Lai, and P. E. Hartmann. 2012. Ultrasonication and the quality of human milk: variation of power and time of exposure. J. Dairy Res. 79:361-366.

Christensen, K. R., and G. A. Reineccius. 1992. Gas chromatographic analysis of volatile sulfur compounds from heated milk using static headspace sampling. J. Dairy Sci. 75:2098-2104.

Clare, D. A., W. S. Bang, G. Cartwright, M. A. Drake, P. Coronel, and J. Simunovic. 2005. Comparison of sensory, microbiological, and biochemical parameters of microwave versus indirect UHT fluid milk during storage. J. Dairy Sci. 88:4172-4182.

Czank, C., K. Simmer, and P. E. Hartmann. 2010. Simultaneous pasteurization and homogenization of human milk by combining heat and ultrasound: effect on milk quality. J. Dairy Res. 77:183-189.

Food and Drug Administration (FDA). 2011. Pasteurized Milk Ordinance. Department of Health and Human Services, US FDA, Silver Spring, MD.
Frankel, E. N. 1980. Lipid oxidation. Prog. Lipid Res. 19:1-22.

Fromm, H. I., and K. J. Boor. 2004. Characterization of pasteurized fluid milk shelf-life attributes. J. Food Sci. 69:M207-M214.

Gandy, A. L., M. W. Schilling, P. C. Coggins, C. H. White, Y. Yoon, and V. V. Kamadia. 2008. The effect of pasteurization temperature on consumer acceptability, sensory characteristics, volatile compound composition, and shelf-life of fluid milk. J. Dairy Sci. 91:1769-1777.

Gao, S., G. D. Lewis, M. Ashokkumar, and Y. Hemar. 2014. Inactivation of microorganisms by low-frequency high-power ultrasound 1. Effect of growth phase and capsule properties of the bacteria. Ultrason. Sonochem. 21:446-453.

García-Risco, M. R., I. Recio, E. Molina, and R. López-Fandiño. 2003. Plasmin activity in pressurized milk. J. Dairy Sci. 86:728-734.

Gogate, P. R. 2011. Application of hydrodynamic cavitation for food and bioprocessing. Pages 141-173 in Ultrasound Technologies for Food Bioprocessing. H. Feng, G. Barbosa-Canovas, and J. Weiss, ed. Springer Science, New York, NY.

Hantsis-Zacharov, E., and M. Halpern. 2007. Culturable psychrotrophic bacterial communities in raw milk and their proteolytic and lipolytic traits. Appl. Environ. Microbiol. 73:7162-7168.

Harvey, E. N., and A. L. Loomis. 1929. The destruction of luminous bacteria by high frequency sound waves. J. Bacteriol. 17:373-376.

Henriques, A. O., and C. P. J. Moran. 2007. Structure, assembly, and function of the spore surface layers. Annu. Rev. Microbiol. $61: 555-588$

Herceg, Z., A. R. Jambrak, V. Lelas, and S. M. Thagard. 2012. The effect of high intensity ultrasound treatment on the amount of Staphylococcus aureus and Escherichia coli in milk. Food Technol. Biotechnol. 50:46-52.

Huck, J. R., B. H. Hammond, S. C. Murphy, N. H. Woodcock, and K. J. Boor. 2007. Tracking spore-forming bacterial contaminants in fluid milk processing systems. J. Dairy Sci. 90:4872-4883.

Huck, J. R., M. Sonnen, and K. J. Boor. 2008. Tracking heat-resistant, cold-thriving fluid milk spoilage bacteria from farm to packaged product. J. Dairy Sci. 91:1218-1228.

Juliano, P., A. E. Torkamani, T. Leong, V. Kolb, P. Watkins, S. Ajlouni, and T. K. Singh. 2014. Lipid oxidation volatiles absent in milk after selected ultrasound processing. Ultrason. Sonochem. 21:2165-2175.

Khanal, S. N., S. Anand, and K. Muthukumarappan. 2014a. Evaluation of high-intensity ultrasonication for the inactivation of endospores of 3 bacillus species in nonfat milk. J. Dairy Sci. 97:59525963.

Khanal, S. N., S. Anand, K. Muthukumarappan, and M. Huegli. 2014b. Inactivation of thermoduric aerobic sporeformers in milk by ultrasonication. Food Control 37:232-239.

Lewis, M. J., and H. C. Deeth. 2009. Heat treatment of milk. Pages 168-204 in Milk Processing and Quality Management. A. Y. Tamime, ed. Wiley-Blackwell Publishing, Hoboken, NJ.

Lopez, P., F. J. Sala, J. L. de la Fuente, S. Condon, J. Raso, and J. Burgos. 1994. Inactivation of peroxidase, lipoxygenase and polyphenol oxidase by manothermosonication. J. Agric. Food Chem. $42: 252-256$.

Manas, P., B. Munoz, D. Sanz, and S. Condon. 2006. Inactivation of lysozyme by ultrasonic waves under pressure at different temperatures. Enzyme Microb. Technol. 39:1177-1182.

Marchesini, F., S. Balzan, F. Montemurro, L. Fasolato, I. Andrighetto, S. Segato, and E. Novelli. 2012. Effect of ultrasound alone or ultrasound coupled with $\mathrm{CO}_{2}$ on the chemical composition, cheesemaking properties and sensory traits of raw milk. Innov. Food Sci. Emerg. Technol. 16:391-397.

Marchesini, G., L. Fasolato, E. Novelli, S. Balzan, B. Contiero, F. Montemurro, I. Andrighetto, and S. Segato. 2015. Ultrasonic inactivation of microorganisms: A compromise between lethal capacity and sensory quality of milk. Innov. Food Sci. Emerg. Technol. 29:215-221.

Martin, N. H., M. L. Ranieri, S. C. Murphy, R. D. Ralyea, M. Wiedmann, and K. J. Boor. 2011. Results from raw milk microbiological tests do not predict the shelf-life performance of commercially pasteurized fluid milk. J. Dairy Sci. 94:1211-1222. 
Martini, S., and M. K. Walsh. 2012. Sensory characteristics and functionality of sonicated whey. Food Res. Int. 49:694-701.

Meer, R. R., J. Baker, F. W. Bodyfelt, and M. W. Griffiths. 1991. Psychrotrophic Bacillus spp. in fluid milk products: A review. J. Food Prot. 54:969-979.

Nguyen, H. A. N., and S. G. Anema. 2010. Effect of ultrasonication on the properties of skim milk used in the formation of acid gels. Innov. Food Sci. Emerg. Technol. 11:616-622.

Patist, A., and D. Bates. 2008. Ultrasonic innovations in the food industry: From the laboratory to commercial production. Innov. Food Sci. Emerg. Technol. 9:147-154.

Pingret, D., G. Durand, A.-S. Fabiano-Tixier, A. Rockenbauer, C. Ginies, and F. Chemat. 2012. Degradation of edible oil during food processing by ultrasound: Electron paramagnetic resonance, physicochemical, and sensory appreciation. J. Agric. Food Chem. 60:7761-7768

Ranieri, M. L., and K. J. Boor. 2009. Short communication: Bacterial ecology of high-temperature, short-time pasteurized milk processed in the United States. J. Dairy Sci. 92:4833-4840.

Ranieri, M. L., J. R. Huck, M. Sonnen, D. M. Barbano, and K. J. Boor. 2009. High temperature, short time pasteurization temperatures inversely affect bacterial numbers during refrigerated storage of pasteurized fluid milk. J. Dairy Sci. 92:4823-4832.

Reiner, J., F. Noci, D. A. Cronin, D. J. Morgan, and J. G. Lyng. 2009a. The effect of thermosonication of milk on selected physiochemical and microstructural properties of yoghurt gels during fermentation. Food Chem. 114:905-911.

Reiner, J., F. Noci, D. A. Cronin, D. J. Morgan, and J. G. Lyng. 2009b. Characterisation of volatile compounds generated in milk by high intensity ultrasound. Int. Dairy J. 19:269-272.

Setlow, P. 2003. Spore germination. Curr. Opin. Microbiol. 6:550-556

Setlow, P. 2006. Spores of Bacillus subtilis: Their resistance to and killing by radiation, heat and chemicals. J. Appl. Microbiol. 101:514525 .

Setlow, P., and E. A. Johnson. 2012. Spores and their significance. Pages 45-79 in Food Microbiology, Fundamentals and Frontiers. M. P. Doyle, and R. Buchanan, ed. 4th ed. ASM Press. Washington, DC.
Shanmugam, A., J. Chandrapala, and M. Ashokkumar. 2012. The effect of ultrasound on the physical and functional properties of skim milk. Innov. Food Sci. Emerg. Technol. 16:251-258.

Soria, A. C., and M. Villamiel. 2010. Effect of ultrasound on the technological properties and bioactivity of food: A review. Trends Food Sci. Technol. 21:323-331.

Vercet, A., J. Burgos, and P. Lopez-Buesa. 2002. Manothermosonication of heat-resistant lipase and protease from Pseudomonas fluorescens: effect of $\mathrm{pH}$ and sonication parameters. J. Dairy Res. 69:243-254.

Vijayakumar, S., D. Grewell, C. Annandarajah, L. Benner, and S. Clark. 2015. Quality characteristics and plasmin activity of thermosonicated skim milk and cream. J. Dairy Sci. 98:6678-6691.

Villamiel, M., and P. de Jong. 2000. Influence of high-intensity ultrasound and heat treatment in continuous flow on fat, proteins, and native enzymes of milk. J. Agric. Food Chem. 48:472-478.

Walstra, P., T. J. Geurts, A. Noomen, A. Jellema, and M. A. J. S. van Boekel. 1999. Heat treatment. Pages 189-209 in Dairy Technology: Principles of Milk Properties and Processes. Marcel Dekker, New York, NY.

Wrigley, D. M., and N. G. Lorca. 1992. Decrease of Salmonella typhimurium in skim milk and egg by heat and ultrasonic wave treatment. J. Food Prot. 55:678-680.

Wu, T. Y., N. Guo, C. Y. Teh, and J. X. W. Hay. 2013. Theory and fundamentals of ultrasound. Pages 5-11 in Advances in Ultrasound Technology for Environmental Remediation. Springer, New York, NY.

Zabbia, A., E. M. Buys, and H. L. De Kock. 2012. Undesirable sulphur and carbonyl flavor compounds in UHT milk. Crit. Rev. Food Sci. Nutr. 52:21-30

Zisu, B., and J. Chandrapala. 2015. High power ultrasound processing in milk and dairy products. Pages 149-179 in Emerging Dairy Processing Technologies: Opportunities for the Dairy Industry. N Datta and P. M. Tomasula, ed. Wiley-Blackwell, Chichester, UK.

Zisu, B., M. Schleyer, and J. Chandrapala. 2013. Application of ultrasound to reduce viscosity and control the rate of age thickening of concentrated skim milk. Int. Dairy J. 31:41-43. 